\title{
Сравнение элементов флеш-памяти с использованием материалов на основе графена
}

\author{
() И.В. Антонова ${ }^{1,2,3}$, И.А. Котин ${ }^{1}$, О.М. Орлов ${ }^{4}$, С.Ф. Девятова ${ }^{1}$ \\ ${ }^{1}$ Институт ффизики полупроводников им. А.О. Ржанова СО РАН, \\ Новосибирск \\ ${ }^{2}$ Новосибирский государственный университет \\ ${ }^{3}$ Новосибирский государственный технический университет \\ ${ }^{4}$ Научно-исследовательский институт молекулярной электроники, Москва \\ E-mail: antonova@isp.nsc.ru
}

Поступило в Редакцию 27 декабря 2016 г.

Исследован захват заряда на тестовые структуры флеш-памяти с плавающими затворами из графена (мультиграфена) и его соединений (оксида графена и частично фторированного графена). Сравнение окна памяти для различных структур показало перспективность использования восстановленного оксида графена, мультиграфена и фторографена. Частично фторированный графен впервые был использован в качестве плавающего затвора в структурах флешпамяти. Материалы на основе графена перспективны для 2D-печатных технологий и гибкой электроники.

DOI: 10.21883/PJTF.2017.19.45080.16623

Флеш-память традиционно занимает одно из ведущих мест среди различных типов элементов энергонезависимой памяти. Недавно было показано, что крайне перспективной заменой материала для плавающего электрода полевого транзистора в элементах флеш-памяти является слой графена или мультиграфена [1,2], а также оксида графена или восстановленного оксида графена [3-5]. Графен (и особенно мультиграфен) как полуметалл способен захватить существенно больший заряд, чем поликремний, нитрид кремния, полупроводниковые нанокристаллы. Благодаря большой работе выхода носителей из графена или мультиграфена (4.6 eV от точки Дирака [6]) формируется высокий потенциальный барьер из $\mathrm{SiO}_{2}$ между графеном и кремнием, который обеспечивает существенное увеличение времени хранения информации на графеновом электроде. Важным является также возможность использования графена 

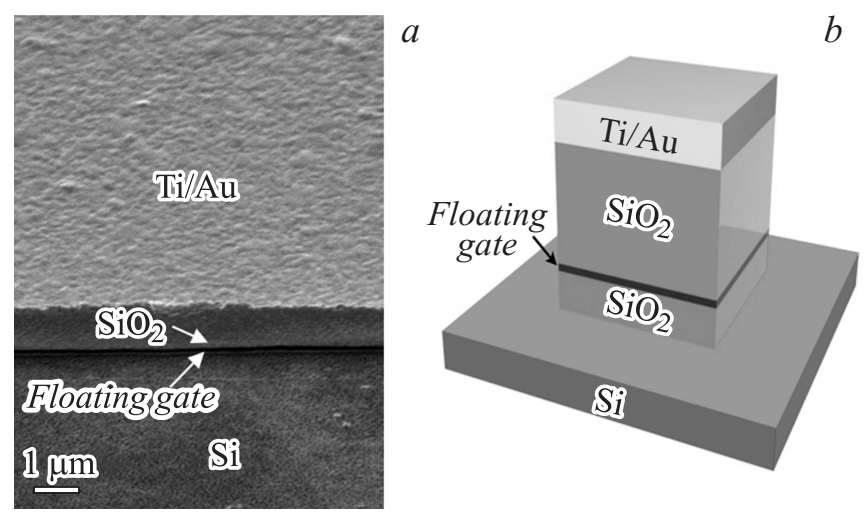

Рис. 1. $a-$ сечение тестового элемента, полученное с помощью сканирующей электронной микроскопии для меза-структуры с использованием оксида графена в качестве плавающего электрода. Угол наклона структуры $45^{\circ} . b-$ схематическое изображение сечения тестовой меза-структуры элементов флешпамяти.

для создания гибкой памяти. Работа элементов флеш-памяти основана на захвате носителей на плавающий электрод в планарном полевом транзисторе. В то же время низкие значения эффективной массы для носителей в мультиграфене и нулевая масса для носителей в графене обеспечивают пикосекундные времена релаксации неравновесных носителей и прохождения носителей через потенциальный барьер между слоями графена [7-9], что способствует быстродействию приборных структур на основе графена.

В настоящей работе исследованы тестовые структуры флеш-памяти (меза-структуры металл-диэлектрик-полупроводник) с плавающим затвором (Gt), изготовленным из оксида графена (GO), восстановленного оксида графена (RGO), фторированного графена (FG), графена (G) и мультиграфена (FLG) и встроенным в диэлектрик тестовых элементов флеш-памяти. Тестовый элемент представлял собой меза-структуру $\mathrm{Au} / \mathrm{Ti} / \mathrm{SiO}_{2} / \mathrm{Gt} / \mathrm{SiO}_{2} / \mathrm{Si}$, схематично показанную на рис. $1, a, b$.

Рис. 1, $a$ представляет сечение тестового элемента, полученное с помощью сканирующей электронной микроскопии для меза-структуры с использованием оксида графена в качестве плавающего электрода. Толщина туннельного $\mathrm{SiO}_{2}$ составляла $3 \mathrm{~nm}$, толщина верхнего бло-

Письма в ЖТФ, 2017, том 43, вып. 19 

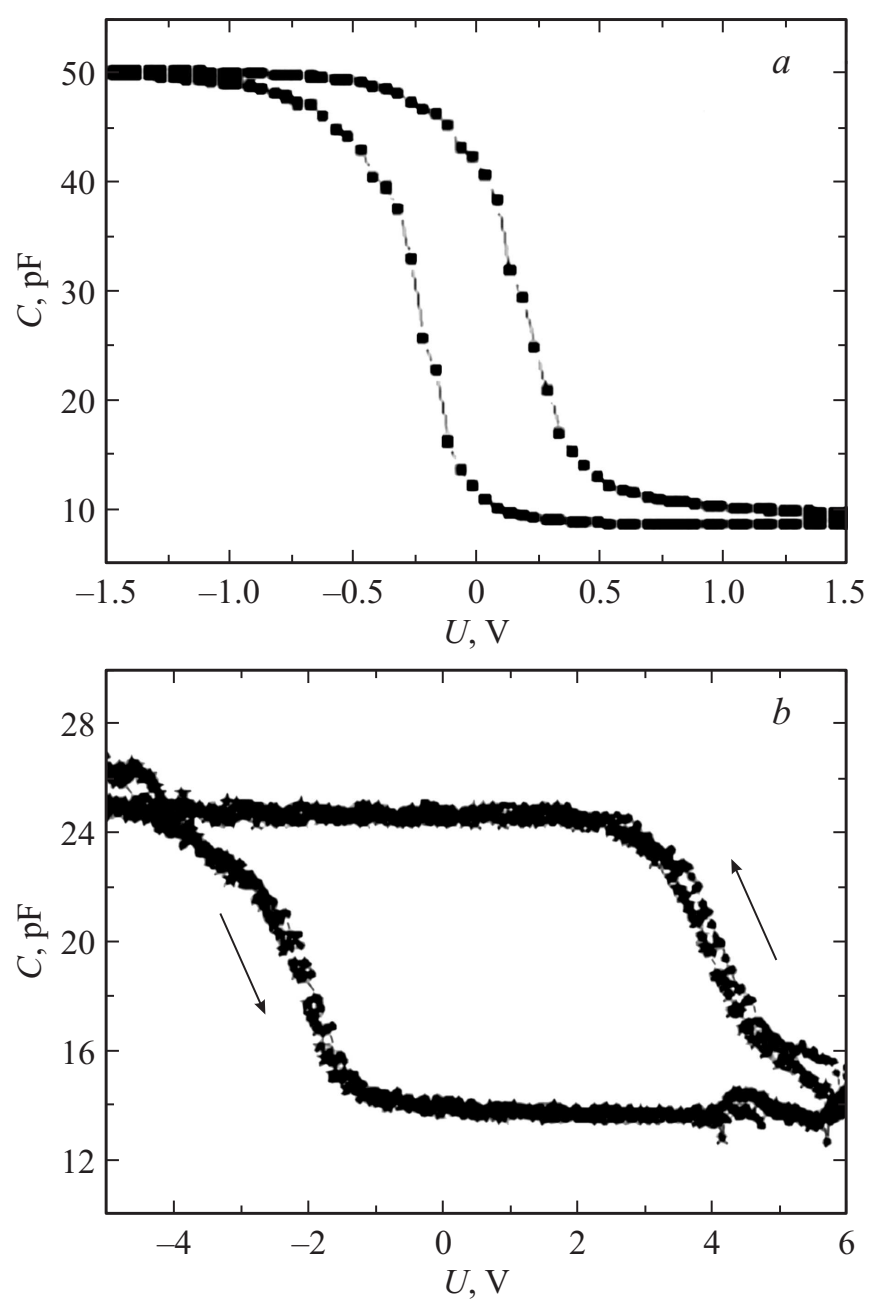

Рис. 2. Вольт-фарадные характеристики меза-структур с GO (a), RGO (b), графеном $(c)$ и мультиграфеном (толщина $2 \mathrm{~nm})(d)$ в качестве плавающего электрода. Толщины GO и RGO составляли $25-30 \mathrm{~nm}$, толщина покрывающего окисла во всех случаях составляла $140 \mathrm{~nm}$. $C-V$-характеристики измерены на частоте $1 \mathrm{MHz}$ и записаны с двухсторонней разверткой напряжения.

Письма в ЖТФ, 2017, том 43, вып. 19 

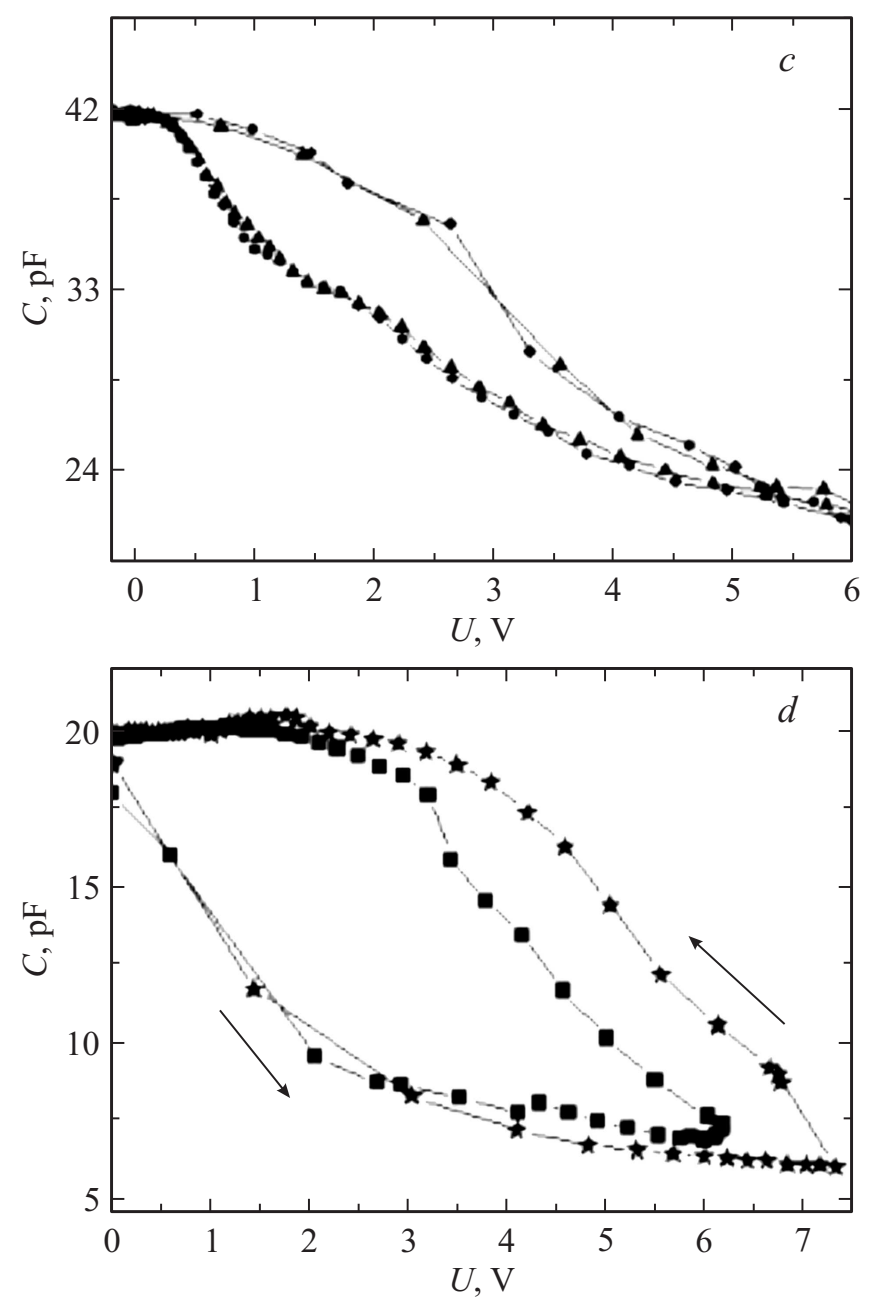

Рис. 2 (продолжение).

кирующего $\mathrm{SiO}_{2}-140 \mathrm{~nm}$. Плавающий затвор в этой структуре был создан из суспензии оксида графена. Затем при температуре $\sim 250^{\circ} \mathrm{C}$ напылялся слой $\mathrm{SiO}_{2}$ (разложение силана) и слой золота с подслоем 
Параметры тестовых меза-структур (заряд, захваченный на плавающие затворы, во всех случаях был отрицательным)

\begin{tabular}{c|c|c|c}
\hline Образец & $\begin{array}{c}\text { Толщина плавающего } \\
\text { затвора, } \mathrm{nm}\end{array}$ & $\begin{array}{c}\text { Окно памяти } \\
\Delta U_{F B}, \mathrm{~V}\end{array}$ & $\begin{array}{c}\text { Изменение заряда } \\
\Delta Q, 10^{11} \mathrm{~cm}^{-2}\end{array}$ \\
\hline G & 0.4 & $1.5-2.0$ & 2 \\
FLG & 2 & $2.8-4.0$ & $2.6-5.5$ \\
FG & $\sim 15-20$ & $1.8-2.5$ & $2.7-4.7$ \\
GO & $\sim 25-30$ & $0.5-0.7$ & $1.4-1.7$ \\
RGO & $\sim 25-30$ & $6-7$ & 12
\end{tabular}

титана. Последующая литография и травление в плазме позволяли получать меза-структуры. Аналогично были получены тестовые структуры с другими плавающими затворами. Для получения структур с восстановленным слоем RGO пластина после нанесения слоя GO была отожжена при температуре $400^{\circ} \mathrm{C}$ в течение часа. Измерения сопротивления отожженного слоя дали величину $250 \mathrm{k} \Omega / \mathrm{sq}$ вместо более $100 \mathrm{M} \Omega$ /sq для исходной пленки. Графен и мультиграфен толщиной $2 \mathrm{~nm}$ были выращены методом химического осаждения из газовой фазы (CVD) и перенесены на подложку с $3 \mathrm{~nm} \mathrm{SiO}_{2}$ с помощью пленки поликарбоната [10]. Фторированный графен был получен путем обработки суспензии графена в водном растворе плавиковой кислоты и представлял собой частично фторированный графен, содержащий квантовые точки графена [11].

На рис. 2 показаны вольт-фарадные $(C-V)$ характеристики мезаструктур с плавающими затворами, изготовленными из различных материалов. Окно памяти для этих структур, определенное как разница напряжений плоских зон $\Delta U_{F B}$, рассчитанных из $C-V$-характеристик при двухсторонней развертке напряжения, приведено в таблице. Из величины напряжения плоских зон был рассчитан заряд, захваченный на плавающий электрод. Полученные значения также представлены в таблице. Окно памяти для GO составило $\Delta U_{F B}=0.5-0.7 \mathrm{~V}$, а для RGO $\Delta U_{F B}=6-7 \mathrm{~V}$ (рис. 2, $\left.a, b\right)$. Плотность поверхностных состояний на границе $\mathrm{SiO}_{2} / \mathrm{Si}$, определенная как изменение заряда при напряжении, соответствующем выходу уровня Ферми к середине зоны $U_{m g}$, составило $\Delta Q=(5-9) \cdot 10^{10} \mathrm{~cm}^{-2}$, что указывает на высокое качество туннельного диэлектрика. На рис. $2, c, d$ представлены $C-V$-характеристики

Письма в ЖТФ, 2017, том 43, вып. 19 
меза-структур с графеном и мультиграфеном толщиной $2 \mathrm{~nm}$. Окно памяти для графена составило $\Delta U_{F B}=1.5-2.0 \mathrm{~V}$, а для мультиграфена $\Delta U_{F B}=2.8-4.0 \mathrm{~V}$. Нужно отметить, что в этом случае значительно возросло напряжение выхода емкости на минимальное значение $U_{m g}$, что свидетельствует о росте состояний на гетерогранице $\mathrm{SiO}_{2} / \mathrm{Si}$, связанном, скорее всего, с процессом переноса графена и мультиграфена на подложку $\mathrm{SiO}_{2} / \mathrm{Si}$.

На рис. 3 представлено изображение поверхности фторографена, а также приведены характерные $C-V$-характеристики структур с пленкой частично фторированного графена, полученной из суспензии. При напряжении более $6-8 \mathrm{~V}$ происходил пробой структур, что не позволяло измерить $C-V$-характеристики полностью. Окно памяти для фторографена составило $\Delta U_{F B}=1.8-2.5 \mathrm{~V}$, что соответствует заряду $\Delta Q=(2.7-4.7) \cdot 10^{11} \mathrm{~cm}^{-2}$.

В таблице суммированы результаты для всех исследованных структур. Наиболее интересные результаты (большое окно памяти и захватываемый заряд) с учетом небольшой толщины слоя $(2 \mathrm{~nm})$ получены для мультиграфена. Самое большое окно памяти имеет восстановленный оксид графена, но в этом случае толщина пленки была относительно большой $(25-30 \mathrm{~nm})$. Неплохой результат получился для фторографена. Нужно отметить, что в последнем случае захват заряда должен зависеть от степени фторирования материала. Так, для оксида графена было показано [12], что захват заряда происходит именно на островки графена в оксиде графена. В работе была использована суспензия со степенью фторирования примерно 50\%. Уменьшение степени фторирования увеличит возможности для захвата носителей, а изоляция отдельных областей графена ослабит влияние дефектов в туннельном и блокирующем окислах, которые обычно приводят к стеканию заряда с плавающего затвора. Возможность использования суспензии фторированного графена для печатных технологий расширяет спектр методов создания и применения приборных структур, в том числе в гибкой электронике. Кроме того, в отличие от графена фторографен является гидрофильным, что позволяет использовать для печати суспензии на водной основе.

Таким образом, проведено сравнение зарядов, захватываемых на плавающие затворы из графена, мультиграфена, оксида графена и частично фторированного графена в тестовых элементах флеш-памяти. Захватываемый заряд увеличивается с ростом толщины плавающего 

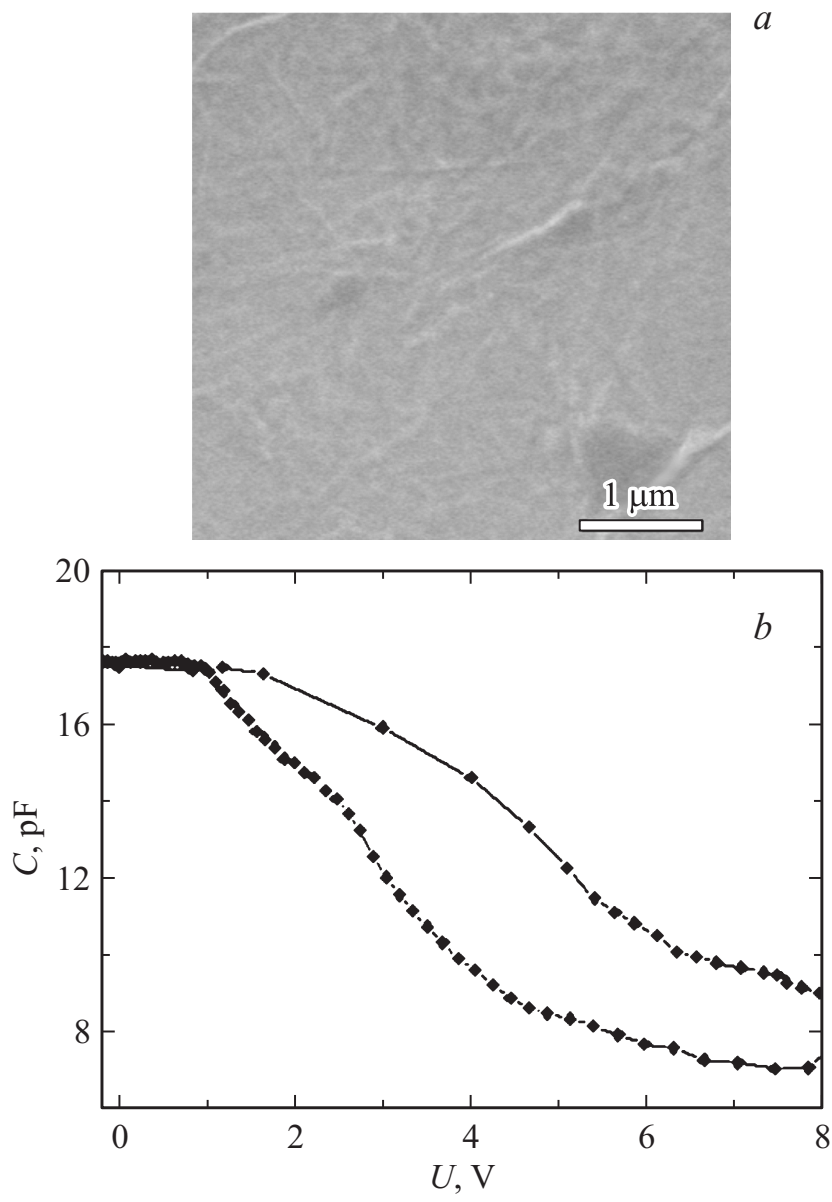

Pис. 3. $a-$ изображение поверхности фторографена, полученное с помощью сканирующей электронной микроскопии, толщина пленки составляла около $15 \mathrm{~nm} . b-$ вольт-фарадная характеристика для структур с фторографеном в качестве плавающего электрода.

затвора и уменьшается с ростом степени функционализации затвора. Выбор материала затвора и степени его фторирования или окисления позволяет оптимизировать структуры флеш-памяти.

4 Письма в ЖТФ, 2017, том 43, вып. 19 
Работа выполнена в рамках проекта Российского фонда фундаментальных исследований (грант № 15-02-02189). Авторы благодарны С.А. Смагуловой (СВФУ) за предоставление суспензии GO.

\section{Список литературы}

[1] Hong A.J., Song K.B., Yu H.S. et al. // ACS Nano. 2011. V. 10. P. 7812.

[2] Choi M.S., Lee G.-H., Yu Y.-J. et al. // Nature Commun. 2013. V. 4. P. 1624.

[3] Sun L., Fugetsu B. // Mater. Lett. 2013. V. 109. P. 207.

[4] Han S.T., Zhou Y., Sonar P. et al. // ACS Appl. Mater. Interfaces. 2015. V. 7. P. 1699.

[5] Abhishek M., Amritha J., Manali K. et al. // IEEE Electron. Dev. Lett. 2013. V. 34. P. 1136.

[6] YuY.-J., Zhao Y., Ryu S., Brus L.E., Kim K.S., Kim P. // Nano Lett. 2009. V. 9. P. 3430.

[7] Dawlaty J.M., Shivaraman S., Chandrashekhar M. et al. // Appl. Phys. Lett. 2008. V. 92. P. 042116.

[8] Breusing M., Kuehn S., Winzer T. et al. // Phys. Rev. B. 2011. V. 83. P. 153410.

[9] Britnell L., Gorbachev R.V., Jalil R. et al. // Science. 2011. V. 335. P. 947.

[10] Антонова И.В., Голод С.В., Соотс Р.А. и др. // ФТП. 2014. Т. 48. С. 827.

[11] Nebogatikova N.A., Antonova I.V., Prinz V.Ya. et al. // Phys. Chem. Chem. Phys. 2015. V. 17. P. 13257.

[12] Kotin I.A., Antonova I.V., Orlov O.M. et al. // Mater. Res. Express. 2016. V. 3. P. 066301. 